\title{
Enhancement of machinability of titanium alloy in the Eductor based PMEDM process
}

\author{
S. Jeavudeen ${ }^{1} \cdot$ H. Siddhi Jailani ${ }^{1} \cdot$ M. Murugan ${ }^{2}$
}

Received: 17 May 2020 / Accepted: 5 March 2021 / Published online: 22 March 2021

(c) The Author(s) $2021 \quad$ OPEN

\begin{abstract}
In this study, an attempt has been made in PMEDM process to sustain the homogeneity in the powder-dielectric mixture irrespective of the nature of the powders, their particle size, concentration etc., The traditional way of powder mixing system in Powder Mixing Electric Discharge Machining (PMEDM) has been refurbished with a novel Eductor based system along with a metering devise to ensure uniform mixing of the powers with the dielectric. Additionally sintered crucible filtration test on the sample of powder-dielectric mixture ensured the presence of known quantity of powders in the dielectric. The experiments are conducted on Titanium alloy with Gap current, Duty factor, Delivery pressure, powder types (Alumina, Silica, and copper) and concentration of these powders as variable process parameters. The output responses, namely material removal rate, tool wear index and surface finish obtained during the machining process have been optimized using AHP-TOPSIS method. The confirmation test indicated that the closeness co-efficient value for the TOPSIS analysis improved by $2.37 \%$ compared with the predicted value.
\end{abstract}

Keyword Eductor $\cdot$ PMEDM · AHP ·TOPSIS · Material removal rate $\cdot$ Tool wear index · Titanium alloy

$\begin{array}{ll}\text { Abbreviations } \\ \text { EDM } & \text { Electrical discharge machining } \\ \text { PMEDM } & \text { Powder mixed electrical discharge machining } \\ \text { MRR } & \text { Material removal rate } \\ \text { TWI } & \text { Tool wear index } \\ \text { AHP } & \text { Analytical hierarchy process } \\ \text { TOPSIS } & \text { Technique for order of preference by similarity } \\ & \text { to the ideal solution } \\ \text { IEG } & \text { Inter electrode gap } \\ \text { Ra } & \text { Arithmetical mean deviation of the profile }\end{array}$

\section{Introduction}

Titanium alloys are considered as one of the important groups in advanced engineering materials owing to its outstanding properties such as good strength combined with excellent fracture toughness, low density with good corrosion resistance [1]. Due to such properties they are being widely used in automotive, aerospace, chemical processing, bio-medical and marine industries. They have got remarkable corrosion resistance even at elevated temperature together with high strength-to-weight ratio and bio-compatibility [2]. Despite being extensively used in major industries, Titanium alloys remain a major concern for the industries for their poor machinability due to low thermal conductivity and chemical affinity at elevated temperature resulting in larger tool wear, tool vibrations and lower material removal rate [2]. To overcome these challenges in the machining of titanium alloys, researchers have made several attempts in the conventional machining process but with limited success [3] and also found it uneconomical [4].

Among the unconventional machining processes, electrical discharge machining (EDM) has been widely acknowledged as an effective method of machining

S. Jeavudeen, shiek.zia@gmail.com | ${ }^{1}$ Department of Mechanical Engineering, B. S. Abdur Rahman Crescent Institute of Science and Technology, Chennai, India. ${ }^{2}$ School of Mechanical Engineering, Vellore Institute of Technology, V IT, Vellore, India. 
Titanium as there is no direct contact between the tool and the work material [5] and its capability to machine any material irrespective of its toughness and hardness [6]. Though EDM has been widely used in the machining of hardest materials like Titanium alloy, low efficiency and slow rate of machining have impelled researchers to innovate newer methods in EDM to enhance machinability [7] and one such method is called Powder Mixed EDM (PMEDM). In PMEDM the powder additives in the form of fine particles are mixed with the dielectric and then the mixture is admitted into the spark gap between the tool and the work piece [8] which has been found to be aiding the machinability of the process.

Addition of powder additives into the dielectric alters electric field [9] and the breakdown characteristics, leading to fair distribution of temperature in the work piece and it reduces the magnitude of temperature stresses on the surface of the work piece [10]. The added particles are energized in the electrical field between the tool and the work piece and move in a zig-zag fashion in the space between the work piece and the tool and forms a chain like arrangement causing bridging effect [11]. Thus the powders get charged and accelerated in the electric field and act as a conductor; they gather in clusters in the sparking area [12] and cause early explosion. Adding these powders alters the ionization-deionization feature of the dielectric liquid, which permits more sparking frequency at the spark zone which in turn changes the breakdown strength of the dielectric [8].

Furutania et al., [13] observed that these powders in the electric field resulted in the formation of chain which eventually encouraged the sparking discharge between the electrodes. Various researchers have observed that the performance of PMEDM in terms of machinability has been enhanced by the addition of additive powders with distinct thermo-electrical properties, and at different particle sizes, concentrations, densities etc., [14-16]. Also the thermo-electrical property of the workpiece materials do affects the machinability of the materials [17].

The addition of powder additives lowers the breakdown strength and subsequent widening of spark gap resulting in increase in the sparking frequency which facilitates the easy removal of materials $[18,19]$. Properties of powders like particle size, density, and thermo-electrical properties are a few of the important properties that affect the machinability of the PMEDM process. Many researchers have attempted the design of experiments (DOE) to obtain better machinability [20]. Kumar et al., [21] employed Taguchi method for the betterment of MRR, TWR, and arithmetic mean $R_{a}$ in the machining of super Co 605 with graphite power mixed PMEDM process. Mohanty et al., [22] found that deep cryogenic treatment of electrodes improved the thermal conductivity and micro-hardness of the brass electrode which in-turn enhanced wearing resistance of the tool.

Mishra et al., [23] used MADM based AHP-TOPSIS method to choose the best among the alternatives available under the given circumstances. In the investigation of carbon nanotube (CNT) infused copper electrode in the machining of AISI D2 tool steel, Raj and Prabhu [24] used TOPSIS technique for the multi response optimization. Dewangan et al., [25] used fuzzy-TOPSIS based MADM technique for the multi response optimization in the Electrical Discharge Machining of AISI P20 steel and achieved optimized surface integrity and dimensional accuracy.

Sivapirakasam et al., [26] used fuzzy-TOPSIS technique for the optimization of output responses such as process time, relative wear rate of the electrode, process energy and dielectric consumption in EDM process. In the Electrical Discharge Machining of AISI 304 steel, Huo et al., [27] used TOPSIS approach for the multi response optimization and obtained optimal setting for the surface roughness, white layer thickness and compressive residual stress.

To perform PMEDM process, the following powder mixing systems were used to mix the powders with the dielectric and it is delivered at the spark gap: i) Powder additives have been directly mixed in the machining tank and a stirrer was used to prevent the settling of powders [28, 29], ii) additional secondary tank was employed to mix the additives with the dielectric liquid and a pump was used for the powder-dielectric mixture [30, 31] and iii) tank in tank with an ultrasonic vibrator to maintain the concentration and also to prevent the precipitation of powders at the bottom of the tank [32,33].

The study was conducted to perform a sustainable PMEDM process, which must be capable of mixing all the powders with liquid dielectric at various levels of concentrations that are permissible in the inter electrode gap (IEG). For multi-response optimization in the machinability of Titanium alloy, TOPSIS analysis has been used [34]. Among the multi response optimization techniques, TOPSIS is a well-known multi response optimization technique, which ranks the alternatives and establishes an optimal result. The results obtained from TOPSIS are nearer to optimal value and farther from the nadir solution.

It is observed from the literature survey, that maintaining the homogeneity in the powder-dielectric mixture irrespective of the nature of the powders, their particle size, concentration etc., has not been discussed clearly. Moreover the added powders may affect the impellor and moving parts of the pump which mixes the dielectric with the powders. Kansal et al., [35] pointed in their review article about that the challenges in performing PMEDM due to its higher consumption of powders, environmental issues in disposing the fluid. 
Therefore in this investigation, an attempt has been made to obtain the homogeneous mixing of the powders in PMEDM process by mixing of powders with the dielectric without affecting the primary dielectric circulation and thereby preventing entry of the powders into impellor of the pump. The machining parameters of the Eductor based PMEDM process are optimized using AHP-TOPSIS method.

\section{Experimental procedure}

\subsection{Design of Novel Eductor based PMEDM process}

The experimental set-up and the schematic diagram of Eductor used for the effective mixing of powders with the dielectric are shown in Figs. 1 and 2 respectively. The

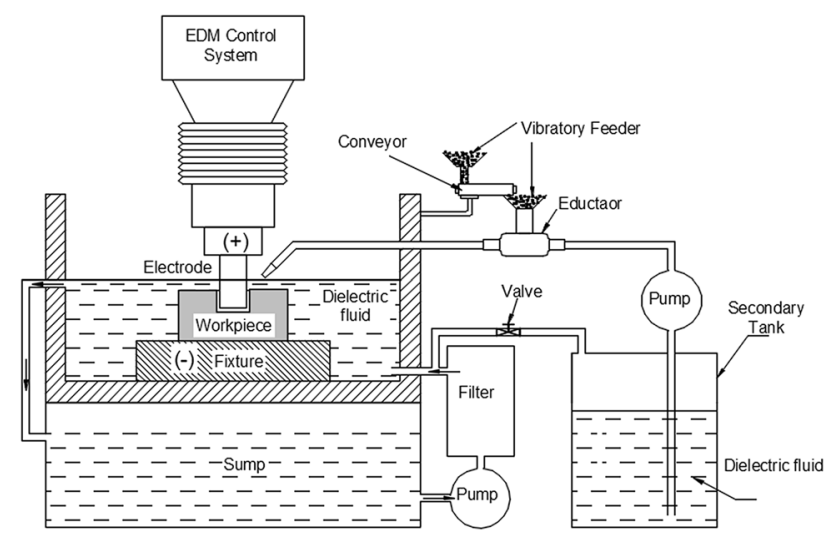

Fig. 1 Eductor based experimental set-up to perform PMEDM process experimental set-up consists of EDM machine (Electronica) with a primary inbuilt tank of $320 \mathrm{~L}$ capacity of recirculating liquid dielectric. A $120 \mathrm{~L}$ secondary tank was furthermore used to mix the powder additives with the dielectric. A low discharge $(<10 \mathrm{lpm})$ and high pressure pump (1-10 Bar) was used to deliver the dielectric into the suction side of the Eductor of the Powder mixing system. An auto transformer ( 3 phase) with variable voltage was used to vary the delivery pressure of the centrifugal pump. This pressurized dielectric was then admitted into a tailor made Powder mixing set-up, at the set pressure, which was capable of mixing liquid with additive powders.

\subsection{Design of Eductor based powder mixing system}

The thorough mixing of selected powders with the dielectric was achieved in the Eductor based powder mixing system. The Eductor based powder mixing system consists of the following components:

- A Metering device: It consists of a hood with a pair of electrically operated vibratory motors. The delivery of the required amount of powder into the screw conveyor was done by the precise controlling of the $D C$ supply to the vibratory motors.

- Screw conveyor: This is also powdered by a DC motor and this delivers the powders continuously to the suction side of the Eductor. Screw conveyor together with the metering device ensures that the selected powders are being delivered at required concentration.

- Eductor: On the motive side the dielectric is pumped in, wherein it goes through the convergent nozzle resulting in low pressure at the suction side. This causes the Eductor to suck the powders which are being delivered
Fig. 2 Schematic layout of Eductor

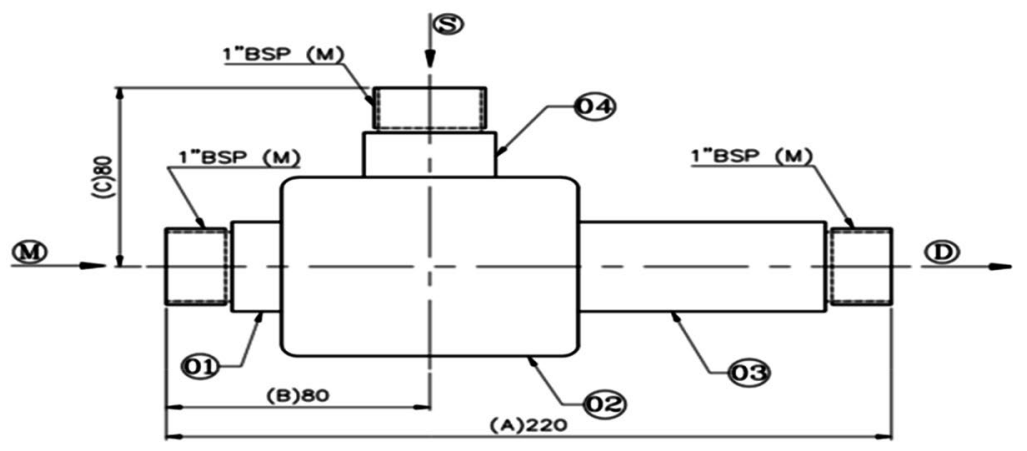

\begin{tabular}{|l|l|l|l|}
\cline { 2 - 4 } \multicolumn{1}{l|}{} & ITEM & DESCRIPTION & MATERIAL \\
\cline { 2 - 4 } $\begin{array}{l}\text { M- MOTIVE SIDE. } \\
\text { D- DUCTION SIDE. }\end{array}$ & 01 & NOZZLE & PTFE \\
\hline 02 & BODY & SS3O4 \\
\hline 03 & DIFFUSER & PTFE \\
\hline 04 & SUCTION & SS3O4 \\
\hline
\end{tabular}


by the screw conveyor resulting in uniform mixing of powders with dielectric at the divergent side of the Eductor. At the delivery end of the Eductor, the powder mixed dielectric liquid is admitted into the tool-work gap.

In the experimental set-up, a customized Tee Type Eductor was used for the mixing of powders with the dielectric. Table 1 illustrates the specifications of the customized Eductor used in the experiment. At the delivery end of the Eductor, the powder-dielectric mixture was collected in known volumes. Later it was tested in a sintered crucible filtration test (Fig. 3) to ensure the presence of the additive powders. The residues that were left on the filter paper of the Bruchner funnel were weighed in an electronic balance to ensure the presence of the additive powders in the correct level of concentration. This further ensures the

Table 1 Specifications of Eductor

\begin{tabular}{lll}
\hline Motive conditions & Motive fluid & EDM oil \\
& Motive temperature & Ambient \\
& Motive flow & 10 lpm at 2 bar \\
& Motive pressure & $2-10 \mathrm{bar}$ \\
Suction conditions & Suction solid & Abrasive Powders \\
& Suction temperature & Ambient \\
& Suction pressure & Atmospheric \\
& Suction flow & 4 lpm \\
Discharge conditions & Discharge tempera- & Ambient \\
& ture & \\
& Discharge & $1 \mathrm{~kg} / \mathrm{cm}^{2}$ \\
Eductor selection & Model & PT-E-1201-CB \\
& Type & Liquid to Solid \\
& Size & $1 " \times 11^{\prime \prime} \times 1 "$ \\
Material of construc- & End connection & Threaded \\
tion & Nozzle \& Diffuser & Teflon \\
& Body & SS304 \\
\hline
\end{tabular}

accuracy of powder mixing system using Eductor based PMEDM set-up.

\subsection{Experiments with Eductor based PMEDM process}

In this system Alumina, Copper, and Silicon Carbide were used as additive powders all at an average particle size of $44 \mu \mathrm{m}$. Necessary precaution was taken so that the powders were free from any volatiles. A cylindrical copper rod of $12 \mathrm{~mm}$ diameter was used as a tool electrode and Titanium alloy of $150 \times 50 \times 7 \mathrm{~mm}$ as work piece material.

Taguchi L18 Orthogonal Array was used for the experiments with Current, Duty Factor, Pressure of the powder mixed dielectric, type of the powder and its concentration as the process parameters with three levels. The factors and its levels used in this study are given in Table 2.

In this study MRR, TWI, and $R_{a}$ were considered as output responses. The material removal rate (MRR) and tool wear rate (TWR) were calculated with the help of an electronic balance (least count of $0.00001 \mathrm{~g}$ ) by observing the difference in mass of the material removed in the work piece and the tool materials per unit time. Surface roughness $\left(R_{a}\right)$ was measured using Taylor Habson Talysurf. The experimental observations for the output responses MRR, TWI, and $R_{a}$ are given in Table 3 .

Table 2 Factors and Levels used in the Eductor based PMEDM setup

\begin{tabular}{llllll}
\hline Factor & Unit & Notation & 1 & 2 & 3 \\
\hline Current & $\mathrm{A}$ & $\mathrm{A}$ & 25 & 30 & 35 \\
Duty factor & $\%$ & $\mathrm{~B}$ & 70 & 80 & 90 \\
Pressure & $\mathrm{Bar}$ & $\mathrm{C}$ & 4 & 6 & 8 \\
Powder type & - & $\mathrm{D}$ & $\mathrm{Al}_{2} \mathrm{O}_{3}$ & $\mathrm{SiC}$ & $\mathrm{Cu}$ \\
Powder concentration & $\mathrm{g} /$ litre & $\mathrm{E}$ & 0 & 2 & 4 \\
\hline
\end{tabular}

Fig. 3 Sintered Crucible Filtration Test

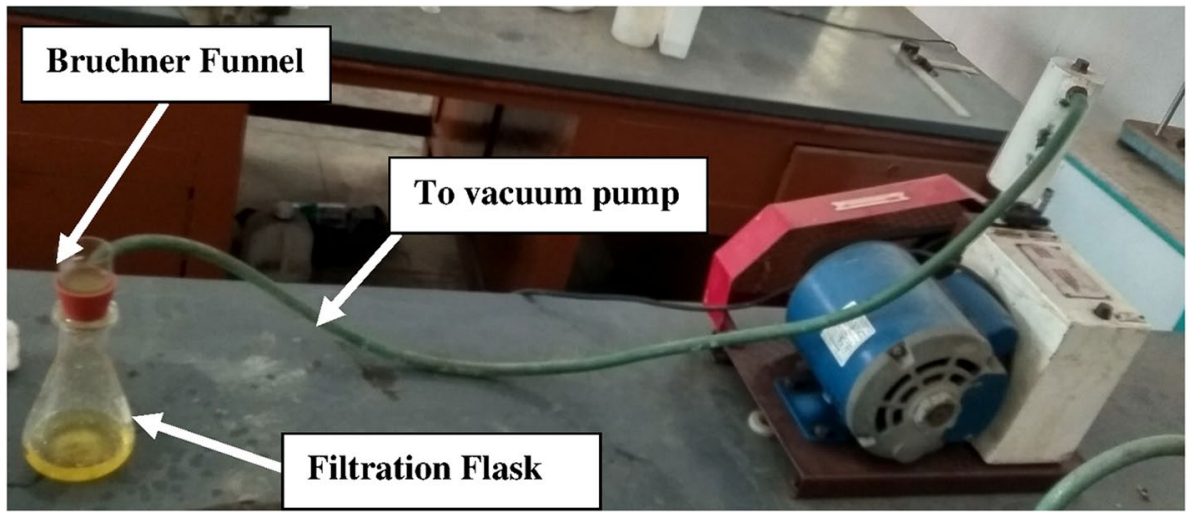


Table 3 Experimental observations in the Eductor based PMEDM process

\begin{tabular}{|c|c|c|c|c|c|c|c|c|}
\hline Exp Nos & Current $(A)$ & $\begin{array}{l}\text { Duty } \\
\text { factor } \\
(\%)\end{array}$ & $\begin{array}{l}\text { Pres- } \\
\text { sure } \\
\text { (Bar) }\end{array}$ & Powder type & $\begin{array}{l}\text { Powder } \\
\text { Conc. (g/ } \\
\text { litre) }\end{array}$ & MRR (g/miute) & TWI & $\mathrm{R}_{\mathrm{a}}(\mu \mathrm{m})$ \\
\hline 1 & 25 & 70 & 4 & $\mathrm{Al}_{2} \mathrm{O}_{3}$ & 0 & 0.019242 & 3.1214 & 8.3863 \\
\hline 2 & 25 & 80 & 6 & $\mathrm{SiC}$ & 2 & 0.018702 & 10.9975 & 7.2706 \\
\hline 3 & 25 & 90 & 8 & $\mathrm{Cu}$ & 4 & 0.055836 & 3.4981 & 6.8627 \\
\hline 4 & 30 & 70 & 4 & $\mathrm{SiC}$ & 2 & 0.026438 & 5.2481 & 9.8612 \\
\hline 5 & 30 & 80 & 6 & $\mathrm{Cu}$ & 4 & 0.062833 & 2.7321 & 7.9602 \\
\hline 6 & 30 & 90 & 8 & $\mathrm{Al}_{2} \mathrm{O}_{3}$ & 0 & 0.024761 & 3.0967 & 8.5261 \\
\hline 7 & 35 & 70 & 6 & $\mathrm{Al}_{2} \mathrm{O}_{3}$ & 4 & 0.117841 & 14.1993 & 9.1817 \\
\hline 8 & 35 & 80 & 8 & $\mathrm{SiC}$ & 0 & 0.041036 & 2.0719 & 8.3493 \\
\hline 9 & 35 & 90 & 4 & $\mathrm{Cu}$ & 2 & 0.059233 & 11.4695 & 7.2527 \\
\hline 10 & 25 & 70 & 8 & $\mathrm{Cu}$ & 2 & 0.033768 & 4.6019 & 8.0270 \\
\hline 11 & 25 & 80 & 4 & $\mathrm{Al}_{2} \mathrm{O}_{3}$ & 4 & 0.025141 & 2.6191 & 8.3516 \\
\hline 12 & 25 & 90 & 6 & $\mathrm{SiC}$ & 0 & 0.012818 & 6.6166 & 7.9955 \\
\hline 13 & 30 & 70 & 6 & $\mathrm{Cu}$ & 0 & 0.021431 & 2.2997 & 5.0957 \\
\hline 14 & 30 & 80 & 8 & $\mathrm{Al}_{2} \mathrm{O}_{3}$ & 2 & 0.051614 & 16.8716 & 8.6795 \\
\hline 15 & 30 & 90 & 4 & $\mathrm{SiC}$ & 4 & 0.033795 & 3.2697 & 8.6058 \\
\hline 16 & 35 & 70 & 8 & $\mathrm{SiC}$ & 4 & 0.015718 & 3.6118 & 11.7461 \\
\hline 17 & 35 & 80 & 4 & $\mathrm{Cu}$ & 0 & 0.032141 & 3.5954 & 7.5059 \\
\hline 18 & 35 & 90 & 6 & $\mathrm{Al}_{2} \mathrm{O}_{3}$ & 2 & 0.049922 & 8.2269 & 9.1005 \\
\hline
\end{tabular}

\subsection{Optimization of Process Parameters for maximizing MRR \& TWI and minimizing $R_{a}$}

In the Eductor based PMEDM process, the experiments were conducted using Taguchi L18 OA. For each trial, a total of 3 experiments were conducted and the mean was taken as the output response for that particular experiment trial for the output responses. These observed data were analysed for their normality and nature of distribution. Main effects plot for the data means were performed to analyse the optimal process parameters for the enhancement of MRR, TWI, and better surface finish. ANOVA was used to assess the contribution of each of the factors. The predicted values of MRR, TWI, and $R_{a}$ were verified by conducting a verification experiment confining to 95\% confidence level.

A typical unmachined surface of the Titanium alloy used in the experiment is shown in the Fig. $4 \mathrm{a}$ and the machined surface of the Titanium alloy with two holes machined in PMEDM process with $12 \mathrm{~mm}$ copper as electrode is shown in the Fig. 4b. The image in the Fig. 4a shows the presence of single phase of isolated lamellar structures in a grain [1].
Fig. 4 Scanning electron micrograph of surface of the Titanium Alloy a Un-machined Surface and b PMEDMed surface

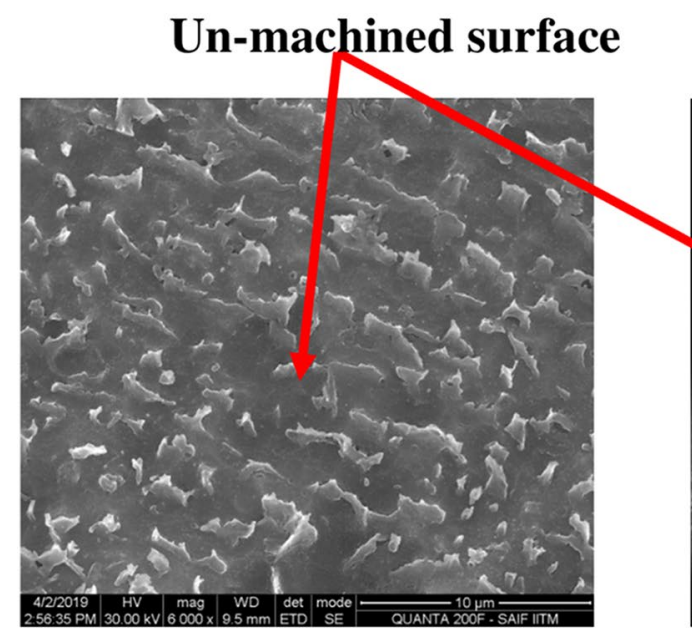

(a)

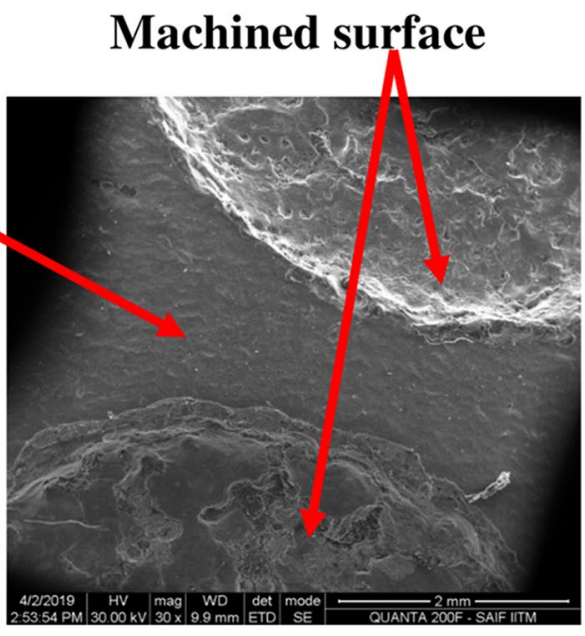

(b) 


\subsubsection{AHP-TOPSIS analysis}

In the Eductor based PMEDM process, three different weight sources for MRR, TWI, and $R_{a}$ were considered. The method required the information about relative importance of properties that were considered in the selection process. This was obtained by pair-wise comparison matrix for the process responses considered. Analytical Hierarchy Process (AHP) [36] theory was used to obtain the relative weight used for each of the output responses used in the experimentation. The AHP method depends on series of pair-wise comparisons considering the observation and assessment of decision makers. Also it is easy to use due to its hierarchical structure; moreover user can give diverse weight for each criterion due to the presence of the pairwise comparison.

The steps involved while performing TOPSIS analysis are as follows [37]:

Step 1: The normalization of the decision matrix is obtained using Eq. 1:

$a_{i j}=\frac{y_{i j}}{\sqrt{\sum_{i=1}^{m} y_{i j}^{2}}}$

$y_{i j}$ is termed the performance measure of $i_{\text {th }}$ alternative with respect to $j_{\text {th }}$ criterion $j=1,2,3, \ldots \ldots . n ; i=1,2,3, \ldots \ldots . m$.

Step 2: The values in the normalized decision matrix are multiplied by the associated weights, $\mathrm{w}_{\mathrm{j}}$, obtained by AHP method; the weighted normalized decision matrix is obtained by Eq. 2 .

$D_{i j}=a_{i j} w_{j} ; \quad j=1,2,3 \ldots n ; i=1,2,3 \ldots m$

Step 3: The ideal and the nadir ideal solutions are obtained using Eqs. 3 and 4 respectively: $\sum E_{i}^{-}=\left\{\sum_{j=1}^{n}\left(B_{i j}-B_{j}^{-}\right)^{2}\right\}^{\frac{1}{2}} j=1,2,3 \ldots n ; i=1,2,3 \ldots m$

Step 5: The closeness co-efficient $\mathrm{CC}_{\mathrm{i}}$ is defined as relative closeness to ideal solution and is obtained by Eq. 7,

$C C_{i}=\frac{E_{i}^{-}}{E_{i}^{+}+E_{i}^{-}} i=1,2,3 \ldots m ; 0 \leq C C_{i} \leq 1$,

The higher values of $\mathrm{CC}_{i}$ indicate the order of rank of each experimental trial in obtaining the solution for a multi response objective function. And the optimal parameter levels were selected from the main effects plot for the closeness coefficient CCi.

\subsection{AHP methodology for the Eductor based powder mixing system}

AHP is used to resolve the multi response optimization of the process parameters. The hierarchical relationships between the goal, responses and the available alternatives are given in Fig. 5. In TOPSIS each of the parameters is multiplied by a weight ' $w_{\mathrm{j}^{\prime}}$ given by Saaty's AHP method. The steps involved in obtaining the weight ${ }^{\prime} w_{j^{\prime}}$ are given below:

Step 1: Since the number of output responses $(n)$ is 3 , $3 \times 3$ Pair-wise comparison Matrix is formed as in Table 4 with each value of the cell as $b_{i j}$. where $\mathrm{b}_{\mathrm{ij}}=$ fundamental scale proposed by Saaty [36]. The column sum is given by $S_{j}=\sum_{1}^{3} b_{i j}$, where $i=1,2,3$ and $j=1,2,3$.

Step 2: Pair-wise comparison matrix is normalized and is given in Table 5. Each cell value $n_{i j}=\frac{b_{i j}}{s_{j}}$, where

$$
\left\{B_{1}^{+}, B_{2}^{+} \ldots \ldots B_{n}^{+}\right\}=\left\{\left(\operatorname{Max}_{i j} \mid j \in C\right),\left(\operatorname{Min}_{i j} \mid j \in C^{\prime}\right) \mid i=1,2,3 \ldots m\right\}
$$

$$
\left\{B_{1}^{-}, B_{2}^{-} \ldots \ldots B_{n}^{-}\right\}=\left\{\left(\operatorname{Min}_{i j} \mid j \in C\right),\left(\operatorname{Max}_{i j} \mid j \in C^{\prime}\right) \mid i=1,2,3 \ldots . m\right\}
$$

where, $C$ is the index set of benefit criteria and $C^{\prime}$ is the index set of cost criteria.

Step 4: Then the distances from the ideal and the nadir solutions are calculated. The two Euclidean distances for each of the alternatives are calculated using Eqs. 5 and 6 respectively:

$$
\sum E_{i}^{+}=\left\{\sum_{j=1}^{n}\left(B_{i j}-B_{j}^{+}\right)^{2}\right\}^{\frac{1}{2}} j=1,2,3 \ldots n ; \quad i=1,2,3 \ldots m
$$

$$
i=1,2,3 \text { and } j=1,2,3 \text {. }
$$

Step 3: Criteria weight $\left(w_{\mathrm{j}}\right)$ is obtained by the mean of summation of values in each of the rows, i.e., $w_{j}=\left(\frac{\sum_{1}^{3} n_{i j}}{3}\right)$, where $i=1,2,3$ and $j=1,2,3$.

Step 4: The weighted sum matrix, the values of $\lambda$ and $\lambda_{\max }$ are given in Table 6 . The consistency index (C.I) [36] is obtained from the weighted sum matrix and is given below: 


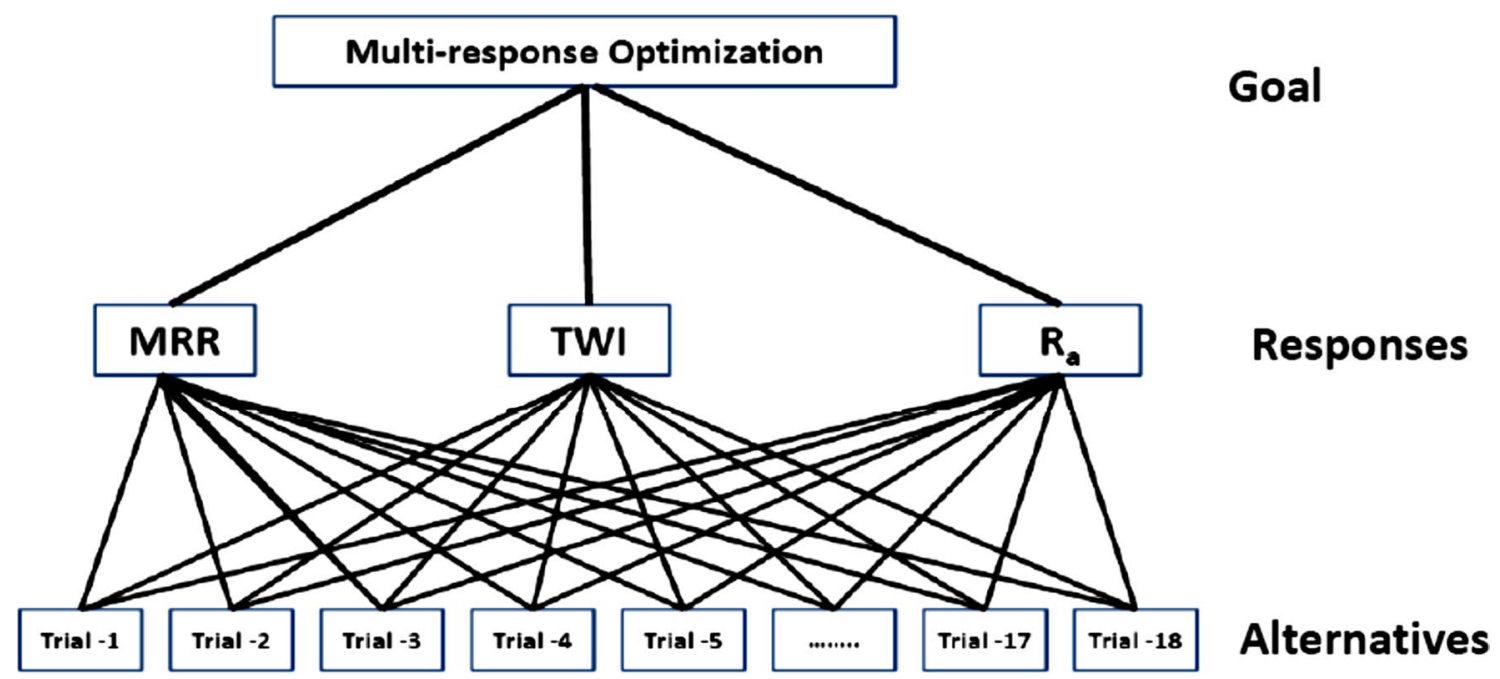

Fig. 5 Hierarchical structure of selection of process parameters by TOPSIS

Table 4 Pair-wise comparison matrix

\begin{tabular}{llll}
\hline & MRR & TWI & $\mathrm{R}_{\mathrm{a}}$ \\
\hline MRR & $1 / 1$ & $3 / 2$ & $2 / 1$ \\
TWI & $2 / 3$ & $1 / 1$ & $2 / 1$ \\
$\mathrm{R}_{\mathrm{a}}$ & $1 / 2$ & $1 / 2$ & $1 / 1$ \\
Column Sum & 2.1667 & 3.0000 & 5.0000 \\
\hline
\end{tabular}

Table 5 Normalized Pair-wise comparison Matrix

\begin{tabular}{lllll}
\hline & MRR & TWI & $\mathrm{R}_{\mathrm{a}}$ & Criteria weight \\
\hline MRR & 0.4615 & 0.5000 & 0.4000 & 0.4538 \\
TWI & 0.3077 & 0.3333 & 0.4000 & 0.3470 \\
$\mathrm{R}_{\mathrm{a}}$ & 0.2308 & 0.1667 & 0.2000 & 0.1991 \\
Sum & 1.0000 & 1.0000 & 1.0000 & 1.0000 \\
\hline
\end{tabular}

Table 6 Weighted sum matrix

\begin{tabular}{lllll}
\hline & MRR & TWI & $\mathrm{R}_{\mathrm{a}}$ & $\Lambda$ \\
\hline MRR & 0.4538 & 0.5205 & 0.3983 & 3.024 \\
TWI & 0.3026 & 0.3470 & 0.3983 & 3.020 \\
$\mathrm{R}_{\mathrm{a}}$ & 0.2269 & 0.1735 & 0.1991 & 3.011 \\
Sum & 1.0000 & 1.0000 & 1.0000 & \\
& & & $\lambda_{\max }$ & $\mathbf{3 . 0 1 8}$ \\
\hline
\end{tabular}

$\lambda_{\max }$ in the bold indicates the value to be used for the selected weight criterion in the Tables 4 and 5
Weighted sum $w s_{i j}=b_{i j} * w_{i}$, where $i=1,2,3$ and $j=1,2,3$.

$\lambda_{\mathrm{i}}=\frac{\sum_{1}^{3} w \mathrm{~s}_{\mathrm{ij}}}{\mathrm{w}_{\mathrm{ij}}}$, where $i=1,2,3$ and $j=1,2,3$.

$\lambda_{\max }=\frac{\sum_{1}^{3} \lambda_{i}}{3}$

Consistency Index (C.I) is given by the relation, $\mathrm{Cl}=\frac{\lambda_{\max }-n}{n-1}$ where $\mathrm{n}=$ number of responses $=3$

$C l=\frac{3.018-3}{3-1}=0.00915$

Step 5: The above consistency index (C.I) is validated by consistency ratio based on Random Index (RI) Table 7. The value of consistency ratio must be less than 0.10 [36].

Consistency Ratio $(C R)=\frac{C l}{\mathrm{Rl}}=\frac{0.00915}{0.58}=0.0158$

The fact that C.R $<0.10$ clearly indicates that the selection of weight criterion ' $w_{j}^{\prime}$ obtained from Table 5 is correct.

Table 7 Random index table

\begin{tabular}{llllllllll}
\hline \multicolumn{10}{l}{ Consistency ratio } \\
\hline $\mathrm{n}$ & 1 & 2 & 3 & 4 & 5 & 6 & 7 & 8 & 9 \\
$\mathrm{RI}$ & 0.00 & 0.00 & 0.58 & 0.9 & 1.12 & 1.24 & 1.32 & 1.41 & 1.45 \\
\hline
\end{tabular}




\subsection{Multi attribute decision making by TOPSIS analysis}

The results of MRR, TWI, and $R_{a}$ obtained from Eductor based PMEDM process are analyzed by TOPSIS method and are as follows:

Step 1: The decision matrix and the normalized decision matrix for the TOSPIS analysis are given in Table 8.

Step 2: The weighted normalized decision matrix is obtained after considering the criteria weight ' $\mathrm{w}_{\mathrm{j}}$ ' obtained from the AHP method and maximum and minimum values in each of the column based on benefit criteria and cost criteria are given in Table 9.

Step 3: Best solution and Nadir solution for each of the output response are given in Table 10.

Step 4: The closeness coefficient and the rank order of the 18 alternatives are given in Table 11.
Table 9 Weighted Normalized Decision Matrix with max and min values

\begin{tabular}{llll}
\hline Exp. No & MRR & TWI & $\mathrm{R}_{\mathrm{a}}$ \\
\hline 1 & 0.0447 & 0.0344 & 0.0470 \\
2 & 0.0435 & 0.1212 & 0.0408 \\
3 & 0.1297 & 0.0386 & 0.0385 \\
4 & 0.0614 & 0.0578 & 0.0553 \\
5 & 0.1460 & 0.0301 & 0.0446 \\
6 & 0.0575 & 0.0341 & 0.0478 \\
7 & 0.2738 & 0.1565 & 0.0515 \\
8 & 0.0953 & 0.0228 & 0.0468 \\
9 & 0.1376 & 0.1264 & 0.0407 \\
10 & 0.0785 & 0.0507 & 0.0450 \\
11 & 0.0584 & 0.0289 & 0.0468 \\
12 & 0.0298 & 0.0729 & 0.0448 \\
13 & 0.0498 & 0.0253 & 0.0286 \\
14 & 0.1199 & 0.1860 & 0.0487 \\
15 & 0.0785 & 0.0360 & 0.0483 \\
16 & 0.0365 & 0.0398 & 0.0659 \\
17 & 0.0747 & 0.0396 & 0.0421 \\
18 & 0.1160 & 0.0907 & 0.0510 \\
Max & 0.2738 & 0.1860 & 0.0286 \\
Min & 0.0298 & 0.0228 & 0.0659 \\
\hline & & &
\end{tabular}

Table 8 Decision \& normalised decision matrices

\begin{tabular}{|c|c|c|c|c|c|c|}
\hline \multirow[t]{2}{*}{ Exp. No } & \multicolumn{3}{|c|}{ Decision matrix } & \multicolumn{3}{|c|}{ Normalized decision matrix } \\
\hline & MRR & TWI & $\mathrm{R}_{\mathrm{a}}$ & MRR & TWI & $\mathrm{R}_{\mathrm{a}}$ \\
\hline 1 & 0.019242 & 3.1214 & 8.3863 & 0.0985 & 0.0992 & 0.2362 \\
\hline 2 & 0.018702 & 10.9975 & 7.2706 & 0.0957 & 0.3493 & 0.2048 \\
\hline 3 & 0.055836 & 3.4981 & 6.8627 & 0.2859 & 0.1111 & 0.1933 \\
\hline 4 & 0.026438 & 5.2481 & 9.8612 & 0.1354 & 0.1667 & 0.2777 \\
\hline 5 & 0.062833 & 2.7321 & 7.9602 & 0.3217 & 0.0868 & 0.2242 \\
\hline 6 & 0.024761 & 3.0967 & 8.5261 & 0.1268 & 0.0984 & 0.2401 \\
\hline 7 & 0.117841 & 14.1993 & 9.1817 & 0.6033 & 0.4510 & 0.2586 \\
\hline 8 & 0.041036 & 2.0719 & 8.3493 & 0.2101 & 0.0658 & 0.2351 \\
\hline 9 & 0.059233 & 11.4695 & 7.2527 & 0.3033 & 0.3643 & 0.2043 \\
\hline 10 & 0.033768 & 4.6019 & 8.0270 & 0.1729 & 0.1462 & 0.2261 \\
\hline 11 & 0.025141 & 2.6191 & 8.3516 & 0.1287 & 0.0832 & 0.2352 \\
\hline 12 & 0.012818 & 6.6166 & 7.9955 & 0.0656 & 0.2102 & 0.2252 \\
\hline 13 & 0.021431 & 2.2997 & 5.0957 & 0.1097 & 0.0730 & 0.1435 \\
\hline 14 & 0.051614 & 16.8716 & 8.6795 & 0.2642 & 0.5359 & 0.2444 \\
\hline 15 & 0.033795 & 3.2697 & 8.6058 & 0.1730 & 0.1039 & 0.2424 \\
\hline 16 & 0.015718 & 3.6118 & 11.7461 & 0.0805 & 0.1147 & 0.3308 \\
\hline 17 & 0.032141 & 3.5954 & 7.5059 & 0.1646 & 0.1142 & 0.2114 \\
\hline 18 & 0.049922 & 8.2269 & 9.1005 & 0.2556 & 0.2613 & 0.2563 \\
\hline
\end{tabular}


Table 10 Best and nadir solutions

\begin{tabular}{|c|c|c|c|c|c|c|}
\hline \multirow[t]{2}{*}{ Exp. No } & \multicolumn{3}{|c|}{ Best solution } & \multicolumn{3}{|c|}{ Nadir solution } \\
\hline & MRR & TWI & $\mathrm{R}_{\mathrm{a}}$ & MRR & TWI & $\mathrm{R}_{\mathrm{a}}$ \\
\hline 1 & 0.05249 & 0.02298 & 0.00034 & 0.00022 & 0.00013 & 0.00036 \\
\hline 2 & 0.05304 & 0.00420 & 0.00015 & 0.00019 & 0.00968 & 0.00063 \\
\hline 3 & 0.02077 & 0.02173 & 0.00010 & 0.00998 & 0.00025 & 0.00075 \\
\hline 4 & 0.04511 & 0.01644 & 0.00071 & 0.00100 & 0.00123 & 0.00011 \\
\hline 5 & 0.01633 & 0.02431 & 0.00026 & 0.01350 & 0.00005 & 0.00045 \\
\hline 6 & 0.04679 & 0.02307 & 0.00037 & 0.00077 & 0.00013 & 0.00033 \\
\hline 7 & 0.00000 & 0.00087 & 0.00052 & 0.05954 & 0.01788 & 0.00021 \\
\hline 8 & 0.03186 & 0.02663 & 0.00033 & 0.00429 & 0.00000 & 0.00036 \\
\hline 9 & 0.01855 & 0.00355 & 0.00015 & 0.01162 & 0.01073 & 0.00064 \\
\hline 10 & 0.03814 & 0.01831 & 0.00027 & 0.00237 & 0.00078 & 0.00044 \\
\hline 11 & 0.04640 & 0.02468 & 0.00033 & 0.00082 & 0.00004 & 0.00036 \\
\hline 12 & 0.05954 & 0.01279 & 0.00026 & 0.00000 & 0.00251 & 0.00045 \\
\hline 13 & 0.05018 & 0.02582 & 0.00000 & 0.00040 & 0.00001 & 0.00139 \\
\hline 14 & 0.02369 & 0.00000 & 0.00040 & 0.00812 & 0.02663 & 0.00030 \\
\hline 15 & 0.03814 & 0.02250 & 0.00039 & 0.00237 & 0.00017 & 0.00031 \\
\hline 16 & 0.05631 & 0.02137 & 0.00139 & 0.00004 & 0.00029 & 0.00000 \\
\hline 17 & 0.03964 & 0.02143 & 0.00018 & 0.00202 & 0.00028 & 0.00057 \\
\hline 18 & 0.02490 & 0.00908 & 0.00050 & 0.00743 & 0.00461 & 0.00022 \\
\hline
\end{tabular}

Table 11 Closeness coefficient and its Rank

\begin{tabular}{|c|c|c|c|c|}
\hline \multirow[t]{2}{*}{ Exp. No } & \multicolumn{2}{|c|}{ Euclidean distance } & \multirow{2}{*}{$\begin{array}{l}\text { Closeness } \\
\text { coeffi- } \\
\text { cient }\end{array}$} & \multirow[t]{2}{*}{ Rank } \\
\hline & Best solution & Nadir solution & & \\
\hline 1 & 0.2753 & 0.0267 & 0.0884 & 17 \\
\hline 2 & 0.2396 & 0.1025 & 0.2996 & 7 \\
\hline 3 & 0.2064 & 0.1048 & 0.3368 & 6 \\
\hline 4 & 0.2495 & 0.0483 & 0.1622 & 13 \\
\hline 5 & 0.2022 & 0.1184 & 0.3693 & 5 \\
\hline 6 & 0.2650 & 0.0350 & 0.1167 & 15 \\
\hline 7 & 0.0373 & 0.2786 & 0.8819 & 1 \\
\hline 8 & 0.2425 & 0.0682 & 0.2195 & 8 \\
\hline 9 & 0.1492 & 0.1516 & 0.5040 & 3 \\
\hline 10 & 0.2382 & 0.0599 & 0.2009 & 9 \\
\hline 11 & 0.2672 & 0.0349 & 0.1155 & 16 \\
\hline 12 & 0.2694 & 0.0544 & 0.1680 & 12 \\
\hline 13 & 0.2757 & 0.0424 & 0.1333 & 14 \\
\hline 14 & 0.1552 & 0.1872 & 0.5467 & 2 \\
\hline 15 & 0.2470 & 0.0534 & 0.1778 & 10 \\
\hline 16 & 0.2812 & 0.0183 & 0.0611 & 18 \\
\hline 17 & 0.2475 & 0.0535 & 0.1777 & 11 \\
\hline 18 & 0.1857 & 0.1107 & 0.3735 & 4 \\
\hline
\end{tabular}

\section{Results and discussions}

\subsection{Influence of Eductor based powder mixing system in PMEDM process}

The Eductor based powder mixing system has been developed to overcome the restrictions faced in the premixing \& pumping type and pump-less gravity type of powder mixing systems for the mixing of powders in the dielectric.. In this study, Taguchi L18 OA was used and the current, duty factor, pressure, powder type and its concentration are considered as process parameters. Since three output responses are considered in this study, AHP-TOPSIS analysis was used to find the closeness-coefficient. The effect of process parameters on the closeness coefficient is discussed as below:

\subsubsection{Effect of current and duty factor on closeness coefficient.}

From Table 11, it is observed that the experiment number 7 is ranked as the best among the 18 alternatives. The main effects plot for the closeness-coefficient is given in Fig. 6 and it is observed that the optimal process parameters obtained using AHP-TOPSIS are $A_{3}-B_{2}-C_{2}-D_{1}-E_{2}$. It is observed from Fig. 6 that the rise in the values of gap current increases the energy available at the spark gap causing more removal of material resulting in larger material removal [38] together with poorer surface finish [39]. Also 
Fig. 6 Main effects plot for closeness coefficient

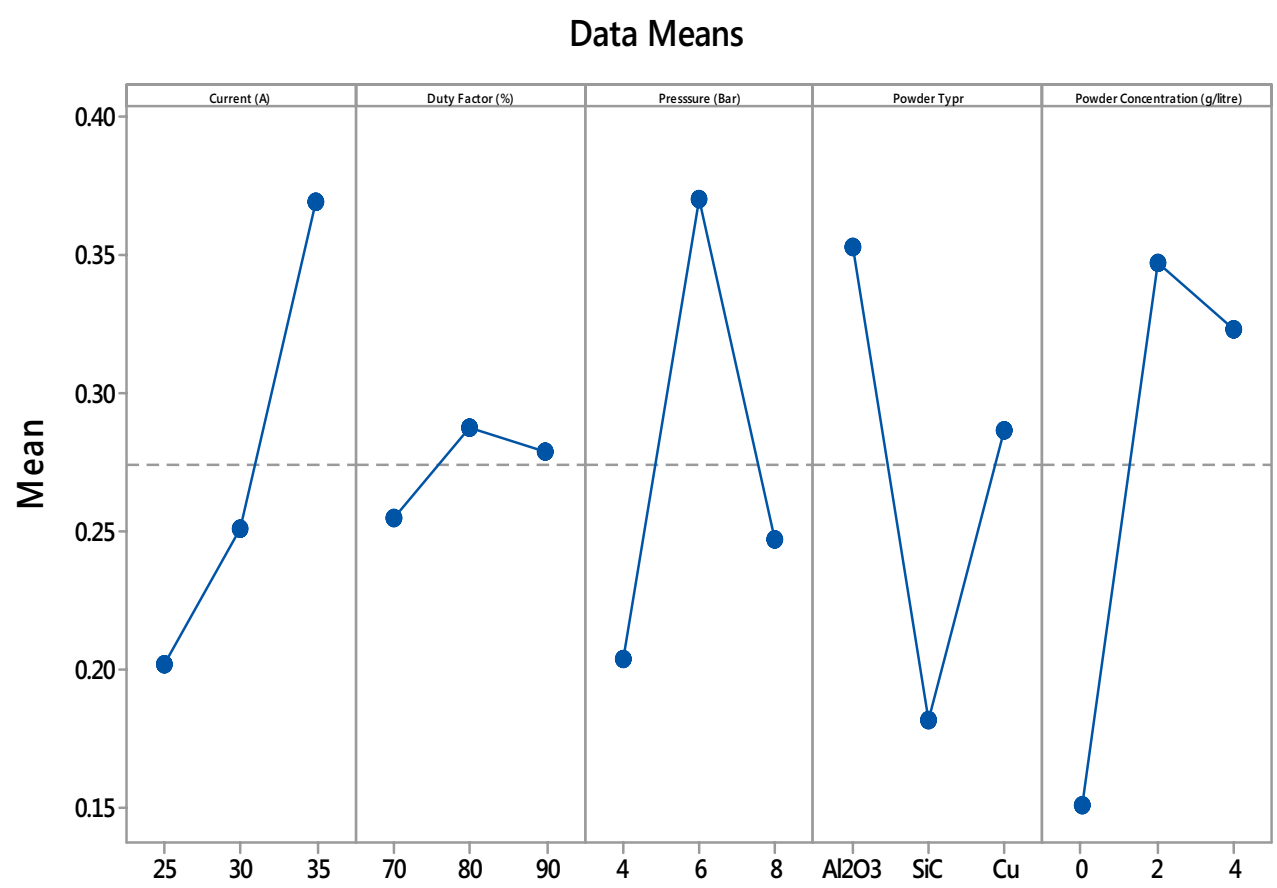

the discharge energy at the machining zone increases with increase in gap current causing higher rate of evaporation and melting of materials [40]. Increase in duty factor enhances the machinability along with poorer surface in the machined parts. This is due to the rise in the temperature of the spark gap causing ionization of the dielectric which causes carbon to be deposited on the tool [41]. This enhances the machinability and affects the surface quality. When the duty factor is increased to $90 \%$, drop in closeness coefficient is observed. This is due to higher value of spark on time which increases the temperature on the surface of the work material which in-turn would have increased its electrical resistivity and possibly deprived its machinability [42].

\subsubsection{Effect of pressurized powder dielectric mixture on closeness coefficient}

Increase in delivery pressure of the liquid dielectric increases the closeness coefficient due to the possible mechanical erosion in addition to spark erosion. However, at the pressure of 8 bar of powder mixed additive particles, the drop in responses occurs due to spark jump caused by it. Also the addition of pressurized powder additives has impacted negatively on the surface finish, probably due to increased force of powder-dielectric causing irregularities on the surface of the work piece. The increased pressure also decreases the spark erosion of material per pulse in successive discharges [43].

\subsubsection{Effect of type of powder and its level concentrations on closeness coefficient}

Among the powders used in the experiment, effect of SiC on the closeness coefficient is lower due to the poor electrical property of SiC. This would possibly have delayed the occurrence of bridging effect and caused breakdown to occur at larger spark voltage giving rise to increase in plasma collision and larger craters [44].

The rise in powder concentration increases the machinability of the titanium work material due to the bridging effect when powders are added. Also, the value of the dynamic viscosity increases leading to the reduction of breakdown strength of the dielectric [45]. It is observed from Fig. 6 that at $4 \mathrm{~g} /$ /itre of powder concentration the collective values of the output responses are less than with $2 \mathrm{~g} /$ litre which may be caused by unstable machining at higher powder concentration. The higher concentration of power may favour MRR, but it will be at the cost of $R_{a}$ resulting drop in closeness coefficient. This is owing to the higher energy at the IEG resulting in possible deeper craters on the surface and will affect the machinability [46].

\subsubsection{Effect of dielectric pressure on recast layer of the work material}

The scanning electron micrograph of the recast layer of the PMEDMed titanium workpiece is shown in te Fig. 7a-c. At a delivery pressure of 4 bar, the recast layer was observed to be uniform with a thickness of (Fig. 7a) $4 \mu \mathrm{m}$. At a pressure of 6 bar, the thickness was observed to be with a marginal 


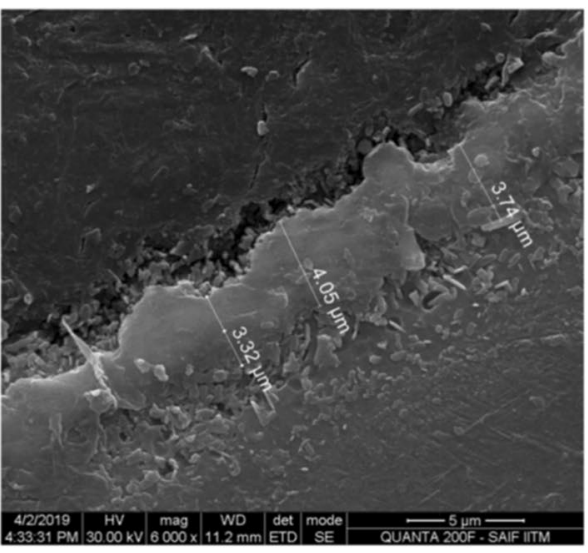

(a) at 4 bar

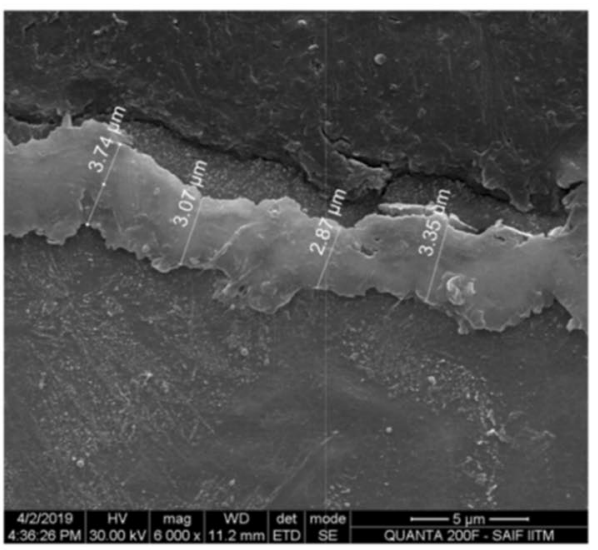

(b) at 4 bar

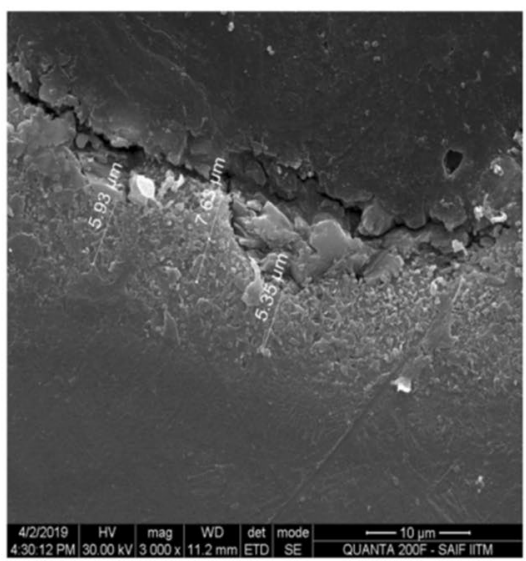

(c) at 4 bar

Fig. 7 Recast Layer of Eductor based PMEDM

Table 12 Results of confirmation test

\begin{tabular}{lll}
\hline & Predicted value by TOPSIS & Experimental value \\
\hline $\begin{array}{l}\text { Closeness co- } \\
\text { efficient }\end{array}$ & 0.8819 & 0.9028 \\
MRR: & $0.117841 \mathrm{~g} / \mathrm{min}$ & $0.105332 \mathrm{~g} / \mathrm{min}$ \\
TWI: & 14.1993 & 16.6932 \\
$\mathrm{R}_{\mathrm{a}}:$ & $9.1817 \mu \mathrm{m}$ & $8.9691 \mu \mathrm{m}$ \\
\hline
\end{tabular}

decrease which is shown in the Fig. 7b. Higher value of delivery pressure of the powder-dielectric would have caused erosion on the surface of the workpiece. But, at the same time when the delivery pressure of the powderdielectric was increased to 8 bar, the decrease in value of machinability as well as surface finish were obtained under variable machining conditions. This possibly due to the formation of uneven recast layer as shown in the Fig. 7c.

\subsection{Confirmation experiment}

The confirmation experiment was conducted based on the optimal process parameters and the results of the confirmation test are given in Table 12. The value of the closeness co-efficient of the confirmation experiment was obtained as 0.9028 which is $2.37 \%$ higher than that of the predicted value.

\section{Conclusions}

- The study embark upon the challenges in the experimental setup used to perform PMEDM process viz., homogeneity of the powder-dielectric mixture, self life of the impellor of pump used to pump the powderdielectric mixture, maintaining concentration at varied levels of particle size, and homogeneity of the mixture when different types of the powder particle were used. These challenges were addressed by designing and developing a novel method of mixing the powder with 
the dielectric called as Eductor based powder mixing system.

- The developed powder mixing system for PMEDM process ensured the isolation of abrasives from rotating parts thereby improving the shelf life of the impellor, proper mixing of the powder with the dielectric and the availability of powder mixed dielectric in the spark zone. Samples collected from the sintered crucible filtration test confirm the presence of metered quantity of powders in the dielectric, thereby ensuring the concentration of the powder-dielectric mixture. The Eductor based PMEDM process was validated by conducting Taguchi L18 experiments with Titanium alloy. The outcome of the study is given below:

- Multi response optimization was performed using AHPTOPSIS method for the Eductor based PMEDM process to identify the optimal level of process parameters. The optimal levels of process parameters were found to be A3-B2-C2-D1-E2 (Gap current-35 A, Duty Factor-80\%, Dielectric Pressure-6 bar, Powder Type$\mathrm{Al}_{2} \mathrm{O}_{3}$, and Powder concentration-2 $\mathrm{g} /$ litre).

- Confirmatory tests have clearly indicated that the value of closeness co-efficient obtained from the confirmation experiment is 0.9028 which is $2.37 \%$ higher than the predicted value.

The above experimental setup and the associated test runs are confined to cylindrical copper electrode, for the selected powders with the concentration upto $4 \mathrm{gms} / \mathrm{litre}$. In future the same setup can be extended to various powders with different level of concentrations, use of multiple tool materials with various tool geometry to find the effect this Eductor based PMEDM setup. Also Fuzzy assisted TOPSIS to be used to predict the further research work.

Acknowledgement We thank the B. S. Abdur Rahman Crescent Institute of Science and Technology for providing the facilities and infrastructure for conducting the experiments.

\section{Declarations}

Conflict of interest The authors declare that they have no conflict of interest.

Open Access This article is licensed under a Creative Commons Attribution 4.0 International License, which permits use, sharing, adaptation, distribution and reproduction in any medium or format, as long as you give appropriate credit to the original author(s) and the source, provide a link to the Creative Commons licence, and indicate if changes were made. The images or other third party material in this article are included in the article's Creative Commons licence, unless indicated otherwise in a credit line to the material. If material is not included in the article's Creative Commons licence and your intended use is not permitted by statutory regulation or exceeds the permitted use, you will need to obtain permission directly from the copyright holder. To view a copy of this licence, visit http://creativecommons. org/licenses/by/4.0/.

\section{References}

1. Davim JP (2014) Machining of titanium alloys. materials forming, machining and tribology. Springer, Berlin

2. Niknam SA, Khettabi R, Songmene V (2014) Chapter 1: machinability and machining of titanium alloys: a review. In Davim JP (ed.), Machining of titanium alloys, 2014. Springer, Berlin, pp $1-30$

3. Hasçalık A, Çaydaş U (2007) A comparitive study of surface integrity of Ti-6AI-4V alloy machined by EDM and AECG. J Mater Process Technol 190(1-3): 173-180.

4. Hasçalık A, Çaydaş U (2007) Electrical discharge machining of titanium alloy (Ti-6Al-4V). Appl Surf Sci 253(22):9007-9016

5. Sun Y, Gong Y, Liu Y, Li Q, Zhou Y (2017) Experimental study on surface characteristics and improvement of microelectrode machined by low speed wire electrical discharge turning. Arch Civ Mech Eng 17(4):964-977

6. Mohd-Abbas N, Solomon DG, Fuad-Bahari M (2007) A review on current research trends in electrical discharge machining (EDM). Int J Mach Tools Manuf 47(7): 1214-1228.

7. Kumar H (2015) Development of mirror like surface characteristics using nano powder mixed electric discharge machining (NPMEDM). Int J Adv Manuf Technol 76(1-4):105-113

8. Jeswani ML (1981) Effect of the addition of graphite powder to kerosene used as the dielectric fluid in electrical discharge machining. Wear 70(2):133-139

9. Haynes WM (2010) CRC handbook of chemistry and physics, 91st edn. Taylor \& Francis

10. Kansal HK, Singh S, Kumar P (2008) Numerical simulation of powder mixed electric discharge machining (PMEDM) using finite element method. Math Comput Model Int J 47(11-12):1217-1237

11. Bhaumik M, Maity K (2019) Effect of deep cryotreated tungsten carbide electrode and $\mathrm{SiC}$ powder on EDM performance of AISI 304. Part Sci Technol 37(8):981-992

12. Chakraborty S, Dey V, Ghosh SK (2015) A review on the use of dielectric fluids and their effects in electrical discharge machining characteristics. Precision Eng 40(Supplement C): 1-6

13. Furutania K, Saneto A, Takezawa H, Mohri N, Miyake H (2001) Accretion of titanium carbide by electrical discharge machining with powder suspended in working fluid. Precis Eng 25(2):138-144

14. Gangadharudu Talla, S Gangopadhayay S, Biswas CK (2017) State of the art in powder-mixed electric discharge machining: a review. Proc Inst Mech Eng Part B J Eng Manuf 231(14): 2511-2526

15. Kung K-Y, Horng J-T, Chiang K-T (2009) Material removal rate and electrode wear ratio study on the powder mixed electrical discharge machining of cobalt-bonded tungsten carbide. Int J Adv Manuf Technol 40(1-2):95-104

16. Tzeng Y-F, Lee C-Y (2001) Effects of powder characteristics on electrodischarge machining efficiency. Int J Adv Manuf Technol 17(8):586-592

17. Jeavudeen S, Siddhi Jailani H, Murugan M (2019) Influence of thermo-electrical property of materials on powder mixed electrical discharge machining. FME Trans 47(3):518-523

18. Bhattacharya A, Batish A, Kumar N (2013) Surface characterization and material migration during surface modification of die steels with silicon, graphite and tungsten powder in EDM process. J Mech Sci Technol 27(1):133-140 
19. Jahan MP, Rahman M, Wong YS (2010) Modelling and experimental investigation on the effect of nanopowder-mixed dielectric in micro-electrodischarge machining of tungsten carbide. Proc Inst Mech Eng B J Eng Manuf 224(11):1725-1739

20. Gaikwad V, Jatti VS (2018) Optimization of material removal rate during electrical discharge machining of cryo-treated NiTi alloys using Taguchi's method. J King Saud Univ Eng Sci 30(3):266-272

21. Singh AK, Kumar S, Singh VP (2014) Optimization of parameters using conductive powder in dielectric for EDM of Super Co 605 with multiple quality characteristics. Mater Manuf Process 29:267-273

22. Mohanty CP, Mahapatra SS, Singh MR (2017) Effect of deep cryogenic treatment on machinability of Inconel 718 in powdermixed EDM. Int J Mach Mach Mater 19(4):343-373

23. Mishra PK, Nadda R, Kumar R, Rana A, Sethi M, Ekileski A (2018) Optimization of multiple arcs protrusion obstacle parameters using AHP-TOPSIS approach in an impingement jet solar air passage. Heat Mass Transf 54(12):3797-3808

24. Oliver Nesa Raj S, Prabhu S (2017) Analysis of multi objective optimisation using TOPSIS method in EDM process with CNT infused copper elctrode. Int J Mach Mach Mater. 19(1): 76-94.

25. Dewangan S, Gangopadhyay S, Biswas CK (2015) Study of Surface Integrity and Dimensional accuracy in EDM using fuzzy topsis and sensitivity analysis. Measurement 63:364-376

26. Sivapirakasam SP, Mathew J, Surianarayanan M (2011) Multi attribute decision making for green electrical discharge machining. Expert Syst Appl 38(7):8370-8374

27. Huo J, Liu S, Wang Y, Muthuramalingam T, Ngoc Pi V (2019) Influence of process factors on surface measures on electrical discharge machined stainless steel using TOPSIS. Mater Res Exp 6(8): 086507

28. Jatti VS, Bagane S (2018) Thermo-electric modelling, simulation and experimental validation of powder mixed electric discharge machining (PMEDM) of BeCu alloys. Alexand Eng J 57(2):643-653

29. Long BT, Phan NH, Cuong N, Jatti VS (2016) Optimization of PMEDM process parameter for maximizing material removal rate by Taguchi's method. Int J Adv Manuf Technol 87(5):1929-1939

30. Jeavudeen S, Siddhi Jailani H, Murugan M (2020) Powder additives influence on dielectric strength of EDM Fluid and Material Removal. Int J Mach Mach Mater 22(1):47-61

31. Ojha K, Garg RK, Chowdary BV (2016) An investigation into surface roughness of work piece produced by chromium powder suspended dielectric in PMEDM process. Int J Manuf Res 11(2):189-208

32. Ou S-F, Wang C-Y (2017) Effects of bioceramic particles in dielectric of powder-mixed electrical discharge machining on machining and surface characteristics of titanium alloys. J Mater Process Technol 245:70-79
33. Pattabhirman A, Marla D, Kapoor G (2016) A computational model to study film formation and debris flushing phenomena in spray-electric discharge machining. J Micro Nano-Manufact4(3): p. 031002-031002-031010.

34. Nguyen PH, Banh TL, Mashood KA et al (2020) Application of TGRA-based optimisation for machinability of high-chromium tool steel in the EDM process. Arab J Sci Eng 45(7):5555-5562

35. Kansal HK, Singh S, Kumar P (2007) Technology and research developments in powder mixed electric discharge machining (PMEDM). J Mater Process Technol 184(1):32-41

36. Saaty TL (1990) How to make a decision: The Analytic Hierarchy Process. Eur J Oper Res 48(1):9-26

37. Ananthakumar, K., D. Rajamani, E. Balasubramanian, and J. Paulo Davim, Measurement and optimization of multi-response characteristics in plasma arc cutting of Monel $400^{\mathrm{TM}}$ using RSM and TOPSIS. Measurement, 2019. 135: p. 725-737.

38. Muthuramalingam T, Mohan B (2015) A review on influence of electrical process parameters in EDM process. Arch Civ Mech Eng 15(1):87-94

39. Dong H, Liu Y, Li M et al (2019) Sustainable electrical discharge machining using water in oil nanoemulsion. J Manuf Process 46:118-128

40. Kong L, Liu Z, Qiu M, Wang W, Han Y, Bai S (2019) Machining characteristics of submersed gas-flushing electrical discharge machining of Ti6Al4V alloy. J Manuf Process 41:188-196

41. Kibria G, Sarkar BR, Pradhan BB, Bhattacharyya B (2010) Comparative study of different dielectrics for micro-EDM performance during microhole machining of Ti-6Al-4V alloy. Int J Adv Manuf Technol 48(5-8):557-570

42. Fonda P, Wang Z, Yamazaki K, Akutsu Y (2008) A fundamental study on Ti-6Al-4V's thermal and electrical properties and their relation to EDM productivity. J Mater Process Technol 202(1):583-589

43. Koyano, T., S. Suzuki, A. Hosokawa, and T. Furumoto, Study on the Effect of External Hydrostatic Pressure on Electrical Discharge Machining. Procedia CIRP, 2016. 42(Supplement C): $p$. 46-50.@@

44. Kunieda M, B. Lauwers, K.P. Rajurkar, and B.M. Schumacher, Advancing EDM through Fundamental Insight into the Process. CIRP Annals, 2005. 54(2): p. 64 - 87.

45. Fontes, D.H., G. Ribatski, and E.P. Bandarra Filho, Experimental evaluation of thermal conductivity, viscosity and breakdown voltage AC of nanofluids of carbon nanotubes and diamond in transformer oil. Diamond and Related Materials, 2015. 58: p. 115-121.

46. Oßwald K, Schneider S, Hensgen L, Klink A, Klocke F (2017) Experimental investigation of energy distribution in continuous sinking EDM. CIRP J Manuf Sci Technol 19:36-43

Publisher's Note Springer Nature remains neutral with regard to jurisdictional claims in published maps and institutional affiliations. 